\author{
УДК 332.144 \\ РЕГИОНЫ С ВЫСОКОЙ КОНЦЕНТРАЦИЕЙ МОНОГОРОДОВ: ПРОБЛЕМЫ ПОВЫШЕНИЯ \\ КАЧЕСТВА ДАННЫХ \\ ирина С. Антонова ${ }^{1, @, ~ * ~}$ \\ ${ }^{1}$ Национальный исследовательский Томский политехнический университет, Россия, 634034, г. Томск, \\ пр. Ленина, 30 \\ @antonovais@tpu.ru
}

Поступила в редакцию 25.03.2018. Принята к печати 17.04.2018.

Ключевые слова: моногород, концентрация, моделирование, пространственное развитие, закон Ципфа.
Аннотация: При всем многообразии исследований проблем развития моногородов качеству статистических данных уделяется сравнительно малое внимание: не учитывается выборочность данных официальной статистики, а также несоответствие территории моногорода муниципальному образованию. Последнее не позволяет применить математические методы для моделирования пространственного развития моногородов. Целью работы является выявление проблем оценки и предложение направлений повышения качества данных о регионах с высокой концентрацией моногородов на примере Кемеровской области. Методы исследования включают сбор и группировку данных по моногородам Кемеровской области с учетом административно-территориального деления региона, построение логарифмической модели распределения городов и моногородов по правилу «ранг-размер» и оценку соответствия полученного распределения правилу Ципфа. В результате исследования автор предлагает направления повышения качества данных о моногородах и получаемых результатов, в частности уточняется соответствие закону Ципфа моногородов Кемеровской области. Результаты могут применяться в области прогнозирования и управления развитием моногородов на региональном уровне.

Для цитирования: Антонова И. С. Регионы с высокой концентрацией моногородов: проблемы повышения качества данных // Вестник Кемеровского государственного университета. Серия: Политические, социологические и экономические науки. 2018. № 3. С. 62-68. DOI:10.21603/2500-3372-2018-3-62-68.

Прошедшее десятилетие (2008-2017 гг.) отмечено ростом интереса к проблемам развития моногородов как в науке, так и на практике, в том числе в управленческой деятельности администраций монопрофильных муниципальных образований, региональных и федеральных органов управления. Несмотря на проведение активной политики в области поддержки моногородов, включающей разработку Комплексных инвестиционных планов модернизации моногородов, обучение управленческих команд администраций моногородов, заключение договоров о сотрудничестве, софинансирование инфраструктурных и отдельных инвестиционных проектов на принципах государственно-частного партнерства, позитивных структурных изменений в экономике регионов пока не происходит, а поиск частных инвестиций редко дает положительный результат.

Высокий интерес научного сообщества к моногородам как объекту исследования объясняется актуальностью проблемы развития данных населенных пунктов в современных социально-экономических условиях развития РФ. Основной для научных разработок становятся работы И. В. Липсица, Е. Г. Аними- цы, В. Я. Любовного, Н. В. Зубаревич, И. Д. Тургель, Г. Д. Антонова, О. П. Ивановой, Е. М. Петриковой, М. Л. Белоножко, Н. И. Крысина и др. В работах определяются понятие «моногород» и критерии выделения моногородов [1-5], проводится анализ социально-экономического развития моногородов [6-7], в том числе на основе обработки официальной статистики [8-9], которая тем не менее имеет ряд недостатков. Так, самые ранние данные, загруженные в систему Росстата по Кемеровской области, датируются 2006 г. (местный бюджет, инвестиции), при этом представлены не все моногорода. Подобные базы данных крайне ограничивают возможность применения математических методов, схожих тем, которые применяют ученые в области региональной экономики, используя базу данных о субъектах Российской Федерации.

Целью данной статьи является выявление проблем оценки и предложение направлений повышения качества данных о регионах с высокой концентрацией моногородов на примере Кемеровской области.

Анализ последних работ, базирующихся на обработке статистических данных о моногородах, показывает различный взгляд на формирование базы данных.

\footnotetext{
* Работа выполнена при поддержке гранта Президента Российской Федерации для молодых ученых № MK-5598.2018.6.
} 
С. Н. Растворцева и И. В. Манаева, проводя проверку закона Ципфа на примере городов и моногородов по показателю объема отгруженной продукции, учитывают лишь 4 моногорода (из 24 монопрофильных населенных пунктов) Кемеровской области, что снижает качество получаемых результатов [7]. В таких условиях дальнейшее развитие научных исследований должно быть направлено на проведение анализа данных с включением максимального числа мониторов за максимальное число лет. Только это условие позволит применить методы математического моделирования динамических особенностей развития данных населенных пунктов и научно обосновать тенденции развития последних.

Н. Ю. Микрюков, напротив, обосновывает исключение из базы данных объема отгруженной продукции в связи с тем, что ему присущ «двойной счет» материалов и услуг, отличающий данный показатель от величины добавленной стоимости [8]. Но исследование, учитывающее исключительно показатели, связанные с численностью населения и занятостью (безработицей), не позволит перейти к полноценному моделированию социально-экономических процессов в моногородах, требующих прочих экзогенных и эндогенных переменных. Таким образом, проблемы формирования базы данных о моногородах и отсутствие общих методических подходов к их комплексному исследованию становится первым, наиболее существенным барьером для исследований в области развития моногородов.

Сформированный официальный перечень монопрофильных населенных пунктов по состоянию на 2017 г. «заморожен» до конца 2018 г. Это обстоятельство позволяет достаточно определенно сформировать перечень моногородов в привязке к регионам. Ранжирование регионов по числу моногородов по- зволяет выделить следующие регионы с наибольшим числом моногородов:

1. Кемеровская область (24 из 66 монопрофильных населенных пунктов в Сибирском федеральном округе).

2. Свердловская область (17 из 37 монопрофильных населенных пунктов в Уральском федеральном округе).

3. Челябинская область (16 из 45 монопрофильных населенных пунктов в Уральском федеральном округе).

4. Нижегородская область (12 из 79 в Приволжском федеральном округе); Кировская область (11 из 79 в Приволжском федеральном округе); Пермский край (10 из 79 в Приволжском федеральном округе), Ивановская область (10 из 63 в Центральном федеральном округе), Брянская область (10 из 63 в Центральном федеральном округе).

Кемеровская область, являясь регионом с максимальным числом монопрофильных населенных пунктов - 24, становится одним из первых потенциальных объектов исследования моногородов, связывающих муниципальный и региональный уровни. Указанное число моногородов особенно за ряд лет позволяет применять методы пространственного моделирования, дисперсионный и корреляционный анализы. Однако включение в базу данных всех 24 муниципальных образований ограничивает специфика статистических данных на муниципальном уровне, а именно агрегирование показателей социально-экономического развития по городским округам (ГО) и муниципальным районам (МР) (таблица). Привлечение данных бухгалтерской отчетности на уровне предприятий позволит агрегировать их на уровне соответствующего монопрофильного населенного пункта (городского округа, города, городского поселения (гп), поселка), а также приблизить экономические показатели к объекту исследования и повысить качество получаемых результатов.

Таблица. Основные показатели экономического развития моногородов в 2016 г. (составлено автором на основе базы данных о муниципальных образованиях Росстата)

Table. The main indicators of economic development of single-industry towns in 2016 (compiled by the author on the basis of the database on municipalities of Federal State Statistics Service (Rosstat)

\begin{tabular}{|c|l|l|l|c|c|c|}
\hline \multirow{2}{*}{ № } & \multicolumn{1}{|c|}{ Перечень } & Статус & $\begin{array}{c}\text { Доступные стати- } \\
\text { стические данные } \\
\text { списочная } \\
\text { численность } \\
\text { занятх, } \\
\text { человек }\end{array}$ & $\begin{array}{c}\text { Оутрузка } \\
\text { сумарно*, } \\
\text { тыс. руб. }\end{array}$ & $\begin{array}{c}\text { Инвестиции, } \\
\text { тыс. руб. }\end{array}$ \\
\hline 1 & Анжеро-Судженский & ГО & по ГО & 15292 & 4302816 & 1079312 \\
\hline 2 & Беловский & ГО & по ГО & 35818 & 59854283 & 4694887 \\
\hline 3 & Березовский & ГО & по ГО & 9162 & 13903143 & 2227250 \\
\hline 4 & Калтанский & ГО & по ГО & 7162 & 4228570 & 529741 \\
\hline 5 & Киселевский & ГО & по ГО & 20090 & 30588125 & 2845566 \\
\hline 6 & Ленинск-Кузнецкй & ГО & по ГО & 27261 & 5153763 & 5088944 \\
\hline 7 & Междуреченский & ГО & по ГО & 33182 & 68138540 & 4448399 \\
\hline 8 & Мысковский & ГО & по ГО & 10506 & 31426444 & 1147228 \\
\hline 9 & Новокузнецкий & ГО & по ГО & 141609 & 31361759 & 16052472 \\
\hline 10 & Полысаевский & ГО & по ГО & 8550 & 10371810 & 3218069 \\
\hline
\end{tabular}




\begin{tabular}{|c|l|l|l|c|c|c|}
\hline № & \multicolumn{1}{|c|}{ Перечень } & Статус & $\begin{array}{c}\text { Доступные стати- } \\
\text { стические данные }\end{array}$ & $\begin{array}{c}\text { Средне- } \\
\text { списочная } \\
\text { численность } \\
\text { занятых, } \\
\text { человек }\end{array}$ & $\begin{array}{c}\text { Отгрузка } \\
\text { суммарно*, } \\
\text { тыс. руб. }\end{array}$ & $\begin{array}{c}\text { Инвестиции, } \\
\text { тыс. руб. }\end{array}$ \\
\hline 11 & Осинниковский & ГО & по ГО & 9000 & 6481853 & 799875 \\
\hline 12 & Прокопьевский & ГО & по ГО & 36313 & 13702137 & 1247335 \\
\hline 13 & Тайгинский & ГО & по ГО & 7730 & 1062991 & 43968 \\
\hline 14 & Юргинский & ГО & по ГО & 18213 & 12535481 & 449717 \\
\hline 15 & Краснобродский & поселок & Краснобродский ГО & 3733 & 9832846 & 1249646 \\
\hline 16 & Таштагол & город & Таштагольский МР & 12366 & 9826848 & 2169306 \\
\hline 17 & Шерегешское & гп & & & & \\
\hline 18 & Мундыбашское & Гп & & & & \\
\hline 19 & Гурьевск & город & Гурьевский МР & 8422 & 1751290 & 270394 \\
\hline 20 & Салаирское & Гп & & & & \\
\hline 21 & Белогорское & гп & Тисульский МР & 3344 & 457700 & 579895 \\
\hline 22 & Мариинск & город & Мариинский МР & 11856 & 11443457 & 1464776 \\
\hline 23 & Топки & город & Топкинский МР & 8973 & 17504156 & 122830 \\
\hline 24 & Яшкинское & гп & Яшкинский МР & 5576 & 11210170 & 740059 \\
\hline
\end{tabular}

Прим.: * отгрузка суммарно определена по добыче полезных ископаемых (раздел С), обрабатывающей промышленности и производству (раздел D), распределению электроэнергии, газа и воды (раздел D) согласно ОКВЭД, ред. 1.

Сбор данных о моногородах в динамике значительно ограничен временными рамками, поскольку официальные статистические данные представлены преимущественно с 2006-2009 гг. Исследованию концентрации видов экономической деятельности за ряд лет мешает смена классификатора ОКВЭД, имевшая место быть в 2016 г., и неравномерное число предприятий, представлявших отчётность в органы статистики. Например, если в период 1999-2005 гг. в информационной базе СПАРК по Анжеро-Судженску представлено лишь 22 предприятия, то в период 2006-2010 гг. 39, 2011-2015 гг. - 152 предприятия. Снижение данных ограничений может быть связано с выделением базового числа предприятий, а также вновь появляющихся, что открывает новые направления исследования в области динамики развития моногородов. Так, всего 16 предприятий Анжеро-Судженска составляют почти 40 \% отгруженной продукции города.

Устранение указанных ограничений и повышение качества формируемых баз исследования позволит уточнить ряд закономерностей, в частности распределение моногородов по закону Ципфа [7; 10].

$$
y=a-b x,
$$

где $y$ - логарифмическая функция ранга $\left(\ln _{\text {ране }}\right) ; x-$ логарифм численности населения $\left(\ln _{\text {размер }}\right) ; b$ - коэффициент Ципфа, показывающий угол наклона зависимости ранга от численности населения городов (моногородов); $a$ - константа.

Закон Ципфа предполагает такое распределение городов по рассматриваемому параметру, что крупнейший город в $n$ раз превосходит $n$-й город по убыванию. Экономический смысл данного закона заключается в возможности применения его для прогнозирования потенциального развития городов (роста или сокращения) по рассматриваемому показателю. Используя данные о численности населения полного числа моногородов Кемеровской области, чего не делалось ранее, в статье предлагается проверить соответствие распределения моногородов по правилу «ранг-размер» на уровне региона, уточнить результаты, полученные авторами ранее [9].

Метод наименьших квадратов позволяет оценить переменные модели. На рисунке 1 представлено распределение «ранг-размер» моногородов по численности населения с учетом всех моногородов из официального перечня (рис. 1).

Наблюдается сильная зависимость показателей ранга и численности населения по всем 24 монопрофильным населенным пунктам. Однако второй, третий и четвертый по величине города (Прокопьевский, Беловский и Междуреченский городские округа соответственно) по численности населения ниже как прогнозного значения, так и эталонного значения (по правилу Ципфа), что может свидетельствовать о потенциальном росте данных городов в будущем. Данная закономерность присуща и остальным моногородам, в целом они показывают более низкую численность населения в сравнении с эталонной.

Добавление Кемеровского городского округа к выборке 24 моногородов усиливает правило «ранг-размер» и повышает коэффициента детерминации при построении прямой распределения $\left(\mathrm{R}^{2}\right)$ с 0,85 до 0,95 , оставляя Новокузнецкий городской округ выше «эталонной» линии.

Построение зависимости «ранг-размер» с включением 39 городских округов и городских поселений 


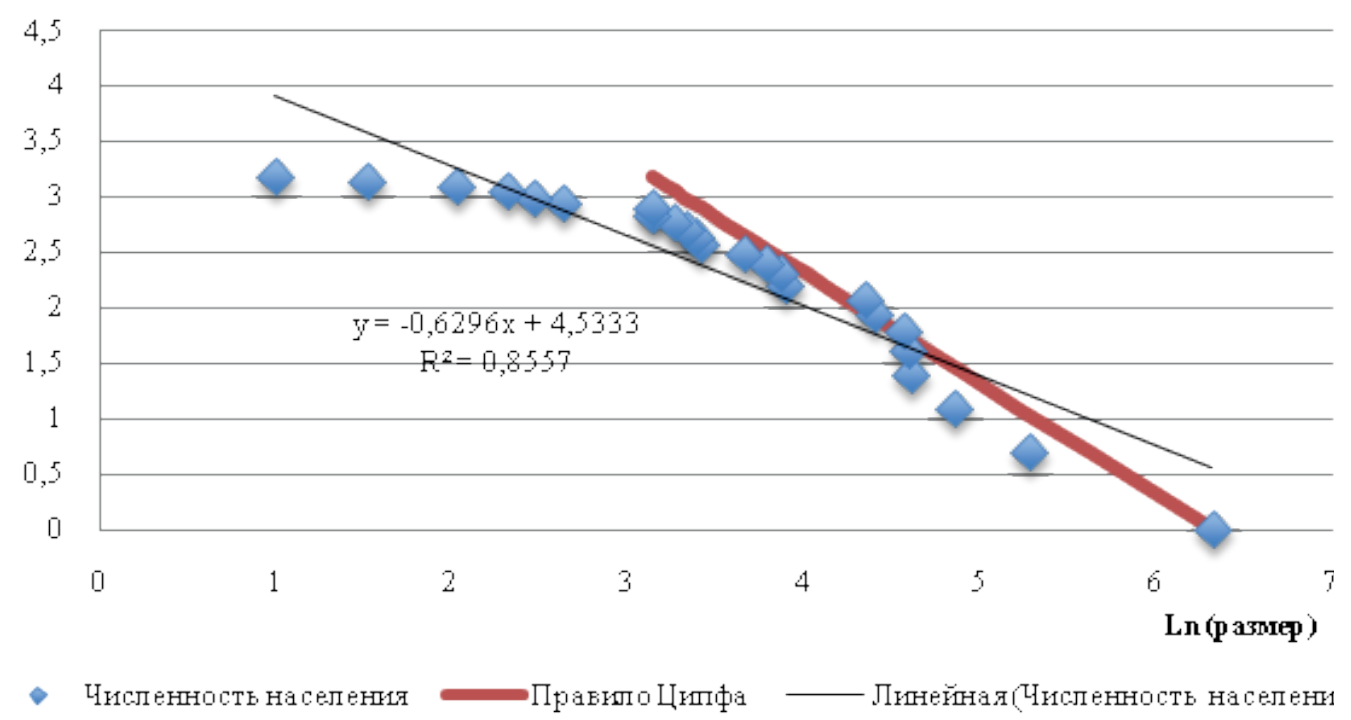

Рис. 1. Распределение «ранг-размер» 24 монопрофильных населенных пункта Кемеровской области по численности населения на 01.01.2017 (составлено автором на основе данных Росстата)

Fig. 1. Distribution of "rank-size" of 24 mono-profile settlements of the Kemerovo Region according to population as of 01.01.2017 (compiled by the author on the basis of Rosstat data)

показывает большую зависимость ранга от размера $\left(\mathrm{R}^{2}=0,92\right)$. Общей тенденцией является более низкая численность населения по сравнению с «эталонным» по всем городам Кемеровской области, кроме Новокузнецкого городского округа (рис. 2). Численность населения Новокузнецкого городского округа почти в 2 раза превосходит «эталонное» значение по закону Ципфа, которое выполняется при коэффициенте $\mathrm{b}=1$ (красная прямая на рисунке 2).

Наибольшую тесноту связи «ранг-размер» демонстрирует выборка из 18 городов и городских округов, входящих в перечень моногородов Кемеровской обла-

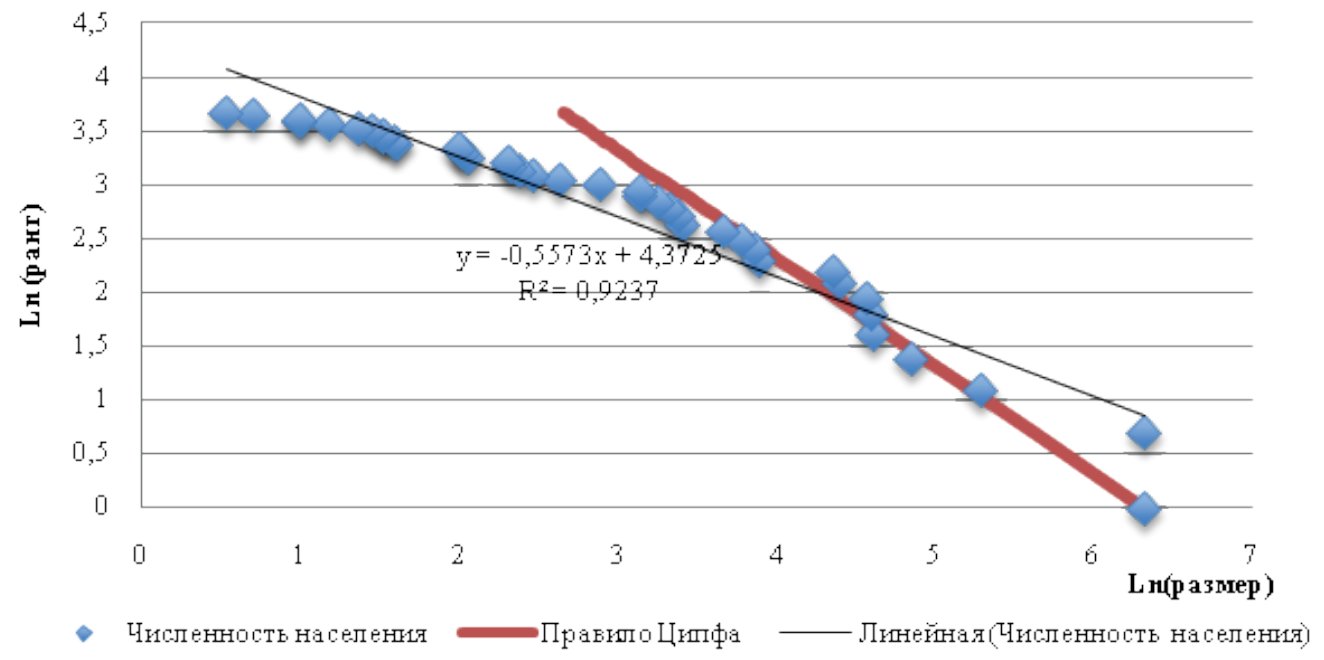

Рис. 2. Распределение «ранг-размер» по 39 городским округам и городским поселениям Кемеровской области по численности населения на 01.01.2017 (составлено автором на основе данных Росстата)

Fig. 2. Distribution of «rank-size» for 39 urban districts and urban settlements of the Kemerovo region by population as of 01.01.2017 (Compiled by the author on the basis of Rosstat data)

сти (т. е. исключая поселения и городские поселения), что представлено на рисунке 3.

Модель распределения моногородов лишь незначительно отклоняется от эталонного значения (по правилу Ципфа) при $b=1$. Коэффициент Ципфа (b) во всех моделях распределения (рис. 1-3) ниже 1, что свидетельствует о том, что численность населения ниже «эталонного» объема по закону Ципфа. Моногорода Кемеровской области, имеющие статус города и городского округа, в большей степени соответствуют закону Ципфа.

Таким образом, выделение регионов с высокой концентрацией моногородов с включением в базу исследования максимального числа моногородов открывает новые перспективы исследования с примене- 


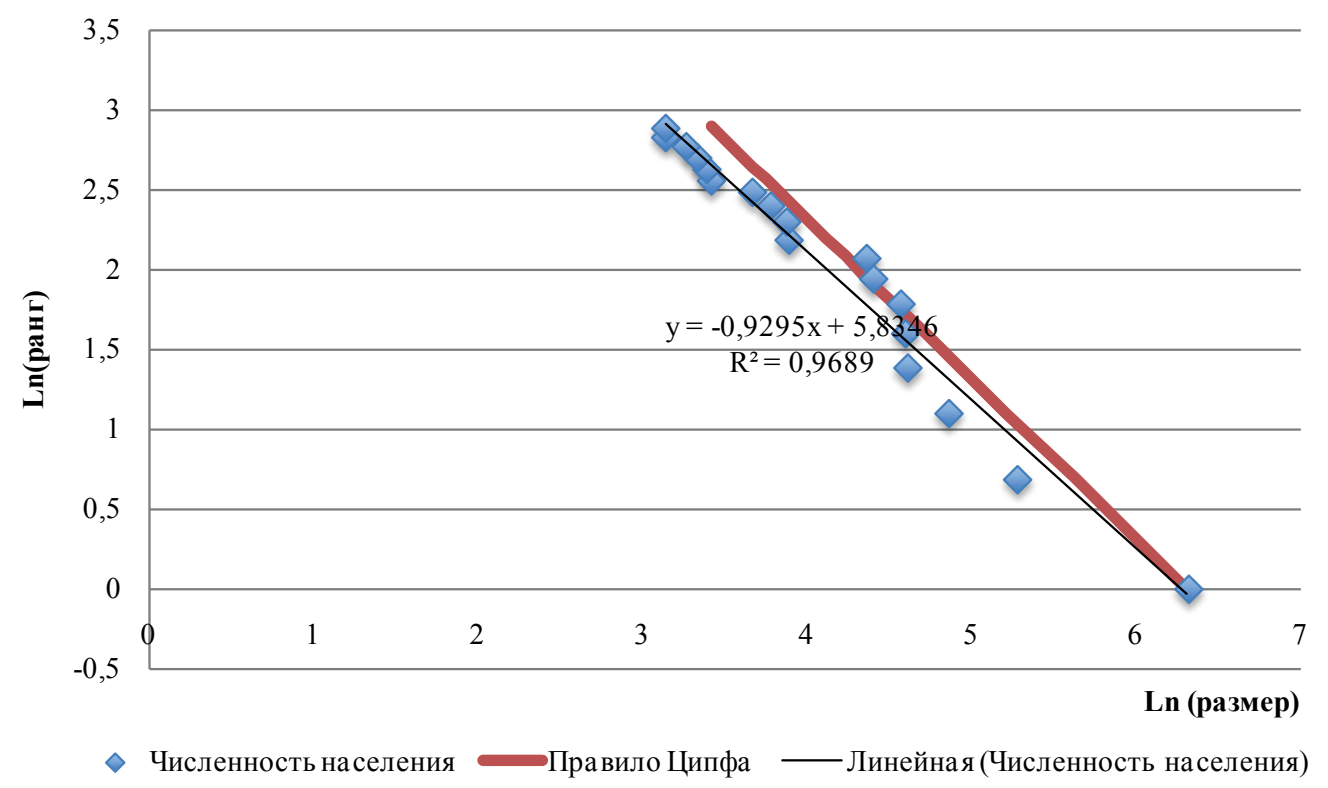

Рис. 3. Распределение «ранг-размер» по 18 городам и городским округам из перечня моногородов Кемеровской области по численности населения на 01.01.2017 (составлено автором на основе данных Росстата)

Fig. 3. Distribution of «rank-size» in 18 cities and urban districts from the list of single-industry towns of the Kemerovo region by population as of 01.01 .2017 (compiled by the author on the basis of Rosstat data)

нием методов математического моделирования. При этом особое значение играет именно качество первоначальных данных в связи с расхождением объектов исследования и уровню агрегирования официальной статистики. Привлечение данных на уровне предприятий позволяет решить данную проблему, однако тре- бует особого внимания к динамике показателей (особенно при смене ОКВЭД). Учет максимального числа населенных пунктов в рамках регионов позволяет, в частности, подтвердить выполнение закона Ципфа по численности населения для всей совокупности моногородов региона на примере Кемеровской области.

\section{Литература}

1. Липсиц И. В. Монопрофильные города и градообразующие предприятия: база данных о градообразующих предприятиях и моногородах России. М.: Издательский дом Хроникер, 2000. 262 с.

2. Тургель И. Д. Проблемы развития моногородов Урала со специализацией в сфере черной металлургии в условиях кризиса // Региональная экономика: теория и практика. 2009. № 26. С. 2-10.

3. Белоножко М. Л., Крысин Н. И. Специфика управления монопрофильными городами Тюменского Севера // Социологические исследования. 2002. № 7. С. 87-91.

4. Кожин В. А., Преснецов А. А., Провалов В. С. Управление социально-экономическим развитием моногорода. Киров: Изд-во Вят. гос. гуманитар. ун-та, 2008. 311 с.

5. Пасынков А. Ф. Разработка сценариев устойчивого социально-экономического развития монопрофильного города сырьевого типа. Екатеринбург: Ин-т экономики УрО РАН, 2006. 54 с.

6. Любовныи В. Я., Кузнецова Г. Ю., Власова Н. И., Гривина И. В. Пути активизации социально-экономического развития монопрофильных городов России. М.: Московский общественный научный фонд, 2004.224 с. (Библиотека местного самоуправления. Вып. 54).

7. Зубаревич Н. В. Регионы России: Неравенство, кризис, модернизация. М.: Независимый институт социальной политики, 2010. $160 \mathrm{c}$.

8. Микрюков Н. Ю. Факторы, проблемы и модели развития моногородов России: автореф. дис. ... канд. геогр. наук; Моск. гос. ун-т им. М. В. Ломоносова, 2016. 26 с.

9. Растворцева С. Н., Манаева И. В. Моногорода в системе размещения производительных сил регионов РФ // Вопросы территориального развития. 2016. № 5. С. 1-9.

10. Петрикова Е. М. Комплексная инвестиционная программа экономики моногорода // Региональная экономика: Теория и практика. 2010. № 43. С. 19-32. 


\title{
REGIONS WITH HIGH CONCENTRATION OF SINGLE-INDUSTRY TOWNS: PROBLEMS OF DATA QUALITY IMPROVEMENT
}

Irina S. Antonova, @, *

\author{
${ }^{1}$ National Research Tomsk Polytechnic University, 30, Lenina Ave., Tomsk, Russia, 634050 \\ @antonovais@tpu.ru
}

Received 25.03.2018. Accepted 17.04.2018.

Keywords: single-industry town, concentration, modelling, spatial development, Zipf's law.

\begin{abstract}
With all the diversity of studies of single-industry towns' development problems, little attention has been given to the quality of statistical data: neither the selective character of official statistics nor the difference between a single-industry town and a municipality are taken into account. The latter makes it impossible to use mathematical methods to simulate the spatial development of towns. The purpose of the current research is to identify the problems of assessment for regions with high concentration of monotowns and to introduce some ways of improving the quality of data by using the case of the Kemerovo region. Research methods include collection and grouping of data on the single-industry towns of the Kemerovo region taking into account the administrative-territorial division of the region, the construction of the logarithmic model of distribution of cities and towns according to the «rank-size» rule and evaluation compliance of the received distribution with the Zipf rule. As a result of research, the author proposes directions of improvement of data on towns and obtained results. In particular, the study specifies the conformity of Kuzbass towns to the Zipf law. The results can be applied in the field of forecasting and management of single-industry towns' development at the regional level.
\end{abstract}

For citation: Antonova I. S. Regiony s vysokoi kontsentratsiei monogorodov: problemy povysheniia kachestva dannykh [Regions with High Concentration of Single-Industry Towns: Problems of Data Quality Improvement]. Bulletin of Kemerovo State University. Series: Political, Sociological and Economic Sciences, no. 3 (2018): $62-68$. DOI:10.21603/2500-3372-2018-3-62-68.

\section{Reference}

1. Lipsits I. V. Monoprofil'nye goroda i gradoobrazuiushchie predpriiatiia: baza dannykh o gradoobrazuiushchikh predpriatiiakh i monogorodakh Rossii [Mono-profile towns and town-forming enterprises: Database of core enterprises and monotowns of Russia]. Moscow: Izdatel'skii dom Khroniker, 2000, 262

2. Turgel' I. D. Problemy razvitiia monogorodov Urala so spetsializatsiei v sfere chernoi metallurgii v usloviiakh krizisa [Problems of development of monotowns of Ural with specialization in steel industry in the conditions of crisis]. Regional'naia ekonomika: teoriia i praktika = Regional economy: theory and practice, no. 26 (2009): 2-10.

3. Belonozhko M. L., Krysin N. I. Spetsifika upravleniia monoprofil'nymi gorodami Tiumenskogo Severa [Specificity of management of mono-profile cities of the north of Tyumen]. Sotsiologicheskie issledovaniia = Sociological Studies, no. 7 (2002): 87-91.

4. Kozhin V. A., Presnetsov A. A., Provalov V. S. Upravlenie sotsial'no-ekonomicheskim razvitiem monogoroda [Management of socio-economic development of monotowns]. Kirov: Izd-vo Viat. gos. gumanitar. un-ta, $2008,311$.

5. Pasynkov A. F. Razrabotka stsenariev ustoichivogo sotsial'no-ekonomicheskogo razvitiia monoprofil'nogo goroda syr'evogo tipa [Development of scenarios of sustainable socio-economic development for monoprofiled towns of raw material type]. Ekaterinburg: In-t ehkonomiki UrO RAN, 2006, 54.

6. Lyubovnyj V. Y., Kuznetsova G. Y., Vlasova N. I., Grivina I. V. Puti aktivizatsii sotsial'no-ekonomicheskogo razvitiia monoprofil'nykh gorodov Rossii [Ways of intensification of social and economic development of mono cities of Russia]. Moscow: Moskovskii obshhestvennyi nauchnyi fond, 2004, 224.

7. Zubarevich N. V. Regiony Rossii: Neravenstvo, krizis, modernizatsiia [Regions of Russia: Inequality, crisis, modernization]. Moscow: Nezavisimyi institut sotsial'noi politiki, 2010, 160.

8. Mikryukov N. Y. Faktory, problemy i modeli razvitiia monogorodov Rossii. Avtoref. diss. kand. geogr. nauk [Factors, problems and models of development of monotowns in Russia. Cand. geogr. Sci. Diss. Abstr.]. Moscow state university. Moscow, 2016, 26.

\footnotetext{
* The research was supported by the grant of the President of the Russian Federation for Young Scientists No. MK-5598.2018.6.
} 
9. Rastvortseva S. N., Manaeva I. V. Monogoroda v sisteme razmeshcheniia proizvoditel'nykh sil regionov RF [Monotowns in the system of placing of productive forces of regions of Russia]. Voprosy territorial'nogo razvitiia = Territorial development issues, no. 5 (2016): 1-9.

10. Petrikova E. M. Kompleksnaia investitsionnaia programma ekonomiki monogoroda [Integrated investment program for economy of a single-industry city]. Regional'naia ekonomika: Teoriia i praktika = Regional Economics: Theory and Pactice, no. 43 (2010): 19-32. 